\title{
Ammonia Removal from Rodent Habitat Operations in Space Using Phosphoric Acid Treated Activated Carbon
}

\author{
Zhe Lu $^{1^{*}}$, Jacob A. Hines ${ }^{2 *}$, Daniel J. Rozewicz ${ }^{1}$, Michael L. Hines ${ }^{3}$ \\ ${ }^{1}$ Lockheed Martin Space OPNS, Moffett Field, USA \\ ${ }^{2}$ University of California, Santa Barbara, USA \\ ${ }^{3}$ NASA Ames Research Center, Moffett Field, USA

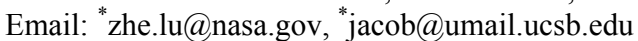

Received October 30, 2013; revised November 29, 2013; accepted December 15, 2013

Copyright (C) 2013 Zhe Lu et al. This is an open access article distributed under the Creative Commons Attribution License, which permits unrestricted use, distribution, and reproduction in any medium, provided the original work is properly cited.

\begin{abstract}
To accommodate long duration biology research with rodent habitats on the International Space Station while providing a healthy living and working environment for crewmembers, NASA Ames Research Center developed a new exhaust filter for odor control for the Animal Enclosure Module (AEM), which houses mice and rats. The new exhaust filter uses activated carbon pellets as adsorbents, with phosphoric acid $\left(\mathrm{H}_{3} \mathrm{PO}_{4}\right)$ impregnated on the surface. The deodorization performance of the new exhaust filters for AEM units housed with mice was evaluated. The ammonia breakthrough time of the exhaust filters was also investigated. The results indicated that $\mathrm{H}_{3} \mathrm{PO}_{4}$ treated activated carbon exhibited a high ammonia adsorption capacity of more than $90 \%$. Furthermore, the new exhaust filter can effectively control the odor from the AEM units for a 45-day (minimum) flight mission with a given animal biomass.
\end{abstract}

Keywords: Activated Carbon; Impregnation; Adsorption; Ammonia; International Space Station

\section{Introduction}

For centuries, humans have observed animals in order to better understand aspects of human biology. In modern times, animal research has become the gold standard for basic biology and medicine. With animal subjects, it is possible to control and reproduce environmental conditions, experimental subjects, and protocol, a set of advantages that is often difficult if not impossible to achieve with human subjects. The value of animal research applies equally well to research in space as it does on the ground. Space animal research is essential for understanding the impacts of spaceflight on physiological systems and for the development of therapies that will mitigate detrimental responses to spaceflight. The rodent, for example, is an ideal surrogate for establishing the temporal baseline effects of long term exposure to spaceflight.

The National Aeronautics and Space Administration (NASA) Animal Enclosure Module (AEM), designed to provide a flight habitat environment for rodents, has been routinely used for spaceflight to conduct rodent microgravity research studies in space. The rodents in the

${ }^{*}$ Corresponding authors.
AEM are a source of numerous airborne contaminants. Odor complaints that have been risen about the rodents involve both the unpleasant character of the odor, as well as the potential adverse health effects.

Although little attempt has been made to identify the chemical composition of the exhaust airstream from the AEM, over 100 chemical compounds have been identified in the airstream from various animal houses [1-4]. Ammonia is one of the major odor causing compounds in animal houses and presents the greatest risk to the environment. It is produced by the decomposition of nitrogen-containing compounds in the excreta, especially in the urine. Levels of $50-100$ ppm of ammonia can cause irritation of eyes, throat, and nose, and has a detection threshold between 5 and 18 ppm for humans [5]. Ammoia levels for a well-ventilated animal house are in the range of 5 to $10 \mathrm{ppm}$ as set by the US Occupational Safety and Health Administration (OSHA) [6]. The Spacecraft Maximum Allowance Concentration (SMAC) of ammonia in the International Space Station (ISS), set by the NASA/JSC Toxicology Group, is $30 \mathrm{ppm}$ for less than 1 hour of exposure and $10 \mathrm{ppm}$ for an exposure of more than 7 days [7].

NASA Ames Research Center (ARC) has undertaken 
the effort to build a new lot of exhaust filters for odor control, especially for ammonia removal, for upcoming long-term science payload missions with AEM payloads.

Many approaches have been tested to mitigate ammonia, but most of them remain on laboratory scales. These techniques include absorption by solutions, separation using membranes, catalytic decomposition, and adsorption by porous solids [8,9]. However, the adsorption on porous solids will be an excellent option to remove ammonia in the flight habitat environment, as liquid solutions are difficult to maintain in space. The ammonia adsorbents are mainly zeolite, activated carbon, and activated alumina. The ammonia adsorption on porous solids can take place through physisorption and chemisorption processes [10]. The chemisorption process is usually stronger than physisorption, because the chemisorption process involves a chemical reaction between ammonia and the adsorbents, while the physisorption process relates to a pore's filling being driven by weak van de Waals forces.

Among the potential ammonia adsorbents, activated carbon is commonly used. Activated carbon exhibits high surface area and highly developed porous structures, which facilitate physical adsorption. Most importantly, strong interactions between the gas and the adsorbent can be enabled by tailoring the porous structure and surface chemistry of activated carbon $[8,11,12]$. The alterations of the activated carbon can be accomplished by impregnation of inorganic compounds, which are anticipated to develop stronger interactions between ammonia and the surface of the activated carbon [13-15]. These impregnants react instantaneously with ammonia in air that has been filtered by previous sorbent layers to remove moisture to form stable chemical compounds that are ireversibly bound to the media as inorganic [16]. The properties of activated carbon will be optimized by the impregnation of suitable chemicals on the internal surface for the chemisorption of certain gases.

The objective of this paper is to present the comprehensive design and configuration of the long-term odiferous organic compound filter, which uses phosphoric acid loaded activated carbon as its adsorbent to remove odorants, especially ammonia. Efforts were made to measure the effectiveness of the long duration exhaust filter designed for odor control. The deodorization performance of the exhaust filters is examined based on 45-day (or longer) science missions in space with mice-loaded AEM units. The lifetime of the exhaust filter will also be explored by testing the time until the odor breakthrough of the exhaust filter.

\section{Experimental}

\subsection{Materials}

New exhaust filters (Figure 1) for the AEM have been assembled and built at NASA Ames Research Center. The exhaust filter is $21.9 \mathrm{~cm} \times 35.5 \mathrm{~cm} \times 6.5 \mathrm{~cm}$ and the flowrate of theairstream from the AEM unitto the exhaust filter was controlled at $0.1 \mathrm{~L} / \mathrm{sec}$.

The exhaust filter in the AEM is designed to prevent the escape of particulate matter into the cabin atmosphere, as well as contain animal odor and neutralize urine within the AEM. The exhaust filter, rated for 45 days of odor control, is made up of 9 layers including Bondina, fabric sorbents, activated carbon, filtrate, and zeolite, as shown in Figure 2. Layer 1 directly exposed to the rodent chamber. This layer, as well as layer 4, consists of phosphoric acid $\left(\mathrm{H}_{3} \mathrm{PO}_{4}\right)$ treated Bondina with 20 g pre-loaded $\mathrm{H}_{3} \mathrm{PO}_{4}$ impregnated on the surface of Bondina for removal of alkaline gas, such as $\mathrm{NH}_{3}$ and amines. Layers 2, 3, 5, and 7 consist of nonwoven fabric with evenly distributed holes for airflow, provide excellent liquidretention and

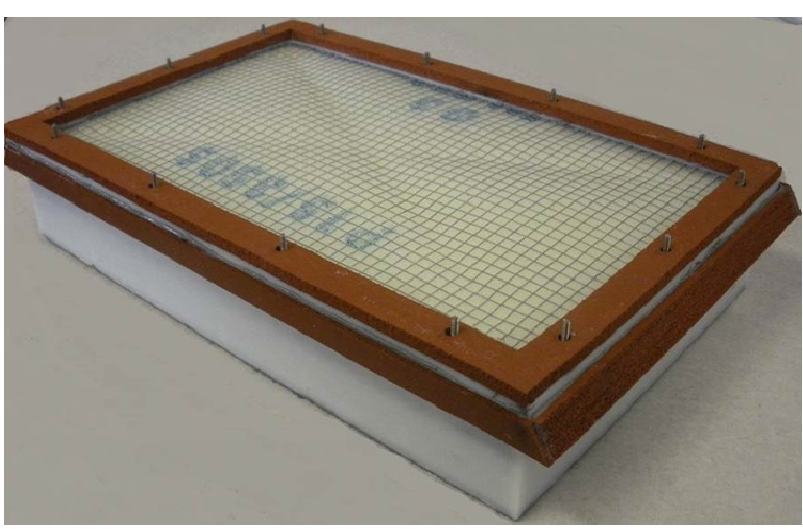

Figure 1. Picture of the exhaust filter for the Animal Enclosure Module (AEM).

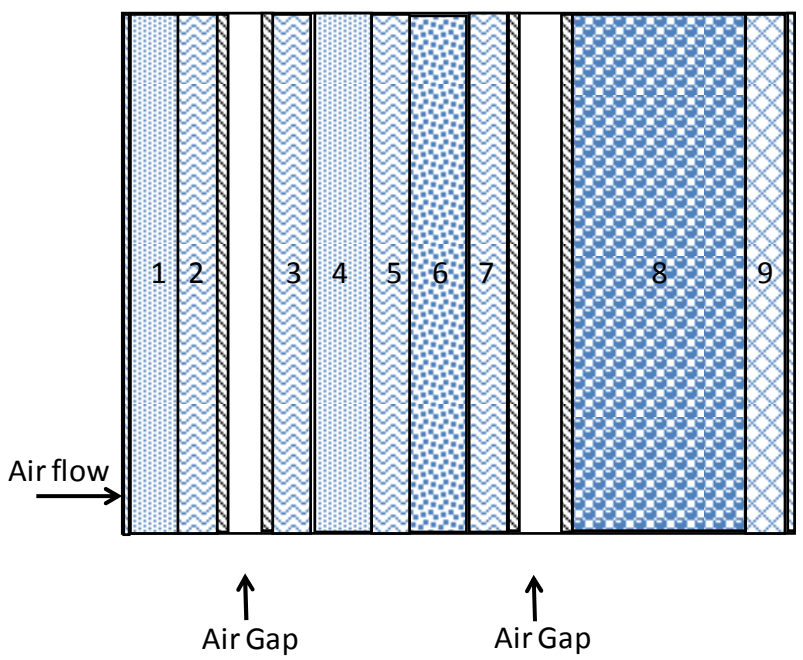

1) Bondina with acid; 2) Sorbent, yellow, punched, with acid; 3) Sorbent, yellow, punched; 4) Bondina with acid; 5) Sorbent, yellow, punched; 6) Zeolite; 7) Universal Sorbent, yellow, punched; 8) Activated Carbon Bed, with acid; 9) G200 Filtrete.

Figure 2. Diagram of the exhaust filter layers for the Animal Enclosure Module (AEM). 
high air flow rate, and are used to stop urine. Air gaps between layers 2 and 3, and layers 7 and 8, were designed to separate fabric filter layers and allow a fast airflow through the layers. Layer 7 contains zeolite pellets from Lewcott Corp, Millbury, MA, which attempt to facilitate the adsorption of both urine and ammonia. Layer 8 is the carbon bed, which is packed with commercially available Ammosorb (NUCON International, Columbus, $\mathrm{OH}$ ), a pelleted, activated carbon with phosphoric acid loaded on the surface to remove alkali gases such as ammonia and amine vapors. The last layer of the exhaust filter is Trion G200 filtrete, which will help to reduce dust, mold spore and odor in the air stream.

Three AEM units (AEM 101, 102, and 103) were loaded with an exhaust filter, mouse food bars, and distilled water, and were used for mice habitat. One AEM unit (AEM 104), had this same setup and was used as a control chamber for the odor evaluation. Ten (10) mice, with 5 mice on each side of the split chamber, were loaded in the three AEM units (101, 102, and 103). All of the four AEM units were instrumented with temperature probes and a gas port for periodic sampling of ammonia $\left(\mathrm{NH}_{3}\right)$, and daily hardware and animal health checks were performed.

The AEM exchanges chamber air with the exhaust filter, a process wherein the air from the rodent cage, previously drawn in through the inlet filter, flows through the exhaust filter prior to exiting the AEM. High efficiency air filters prevent the escape of particulate matter into the cabin atmosphere, and treated activated carboninside the filters helps contain animal odor and neutralize urine within the AEM. After exiting the habitat through the exhaust filter, the filtered air is drawn through the exhaust fans into the cabin.

Gas samples were collected from the gas port that directly connected to the AEM main chamber. Concentrations of $\mathrm{NH}_{3}$ were measured from test day 21 onwards using two Dräger test pumps with a detection range of $0.20-5.0 \mathrm{ppm}$ and $5-70 \mathrm{ppm}$, respectively.

\subsection{Odor Measuring Method}

The odor expelled from the four investigated AEM units was evaluated using panelists to rank samples. A group of volunteers were trained to conduct the daily odor evaluations. An arbitrary scale was used to describe the intensity of the odor from the AEM units. Each AEM unit was covered with a blue shroud to prevent ambient light from entering cage environment and prevented odor panelists from viewing the cage interior.

During the evaluations, sniffers were asked to stand a distance of $6-8$ in from the AEM exhaust outlet and scored the odor using a 5-point scoring system: $0=$ undetectable, 1 = barely detectable, 2 = easily detectable, 3 = objectionable (disagreeable), and $4=$ revolting (ex- tremely offensive). Group training, instruction, and calibration were provided to evaluators prior to the tests. Score selections were based on odor interpretation with respect to predetermined and formerly presented (sniffed) standards for each level of the scoring system. Average odor scores for each test day were then calculated.

The animal tests will be stopped when the average odor scores are over 3.0 for two consecutive days, the mouse food bars need to be replaced, or when the mice are observed to be in bad health, whichever appears first. The breakthrough time of the new exhaust filter will be identified for AEM units 102, 103, and 104 when the average odor scores go over 3.0 for two consecutive days.

\section{Results and Discussions}

Figure 3 shows the odor evaluation results from the AEM units on test days $\mathrm{T}+0$ through $\mathrm{T}+50$. The total number of people in the panel was no less than 12 for any test day. At the beginning of the test $(T+0)$, there was an odor reading of 1.4 for the control AEM unit 104, and 1.05, 1.4, and 1.6 for AEM unit 101, 102, and 103, respectively. This indicated that some individuals identified a background odor, which waslikelythe odor of the mouse food bars, and that the exhaust filters with $\mathrm{H}_{3} \mathrm{PO}_{4}$ treated activated carbon did not effectively remove the odorants in the mouse food bars. We could not comment on the reactions of odorants from mouse food bars against the sorbent materials in the exhaust filter in the present work, as the odor causing compounds in the mouse food bars have not been identified yet.

From test day 7 to 50 , the odor scores of the control AEM unit decreased relative to the first test day and varied in the range of $0.29-0.88$, likely as a result of the dehydration of the mouse food bars with operation time. As indicated Figure 3, the average odor scores of animalloaded AEM units slightly decreased on day 7 for AEM

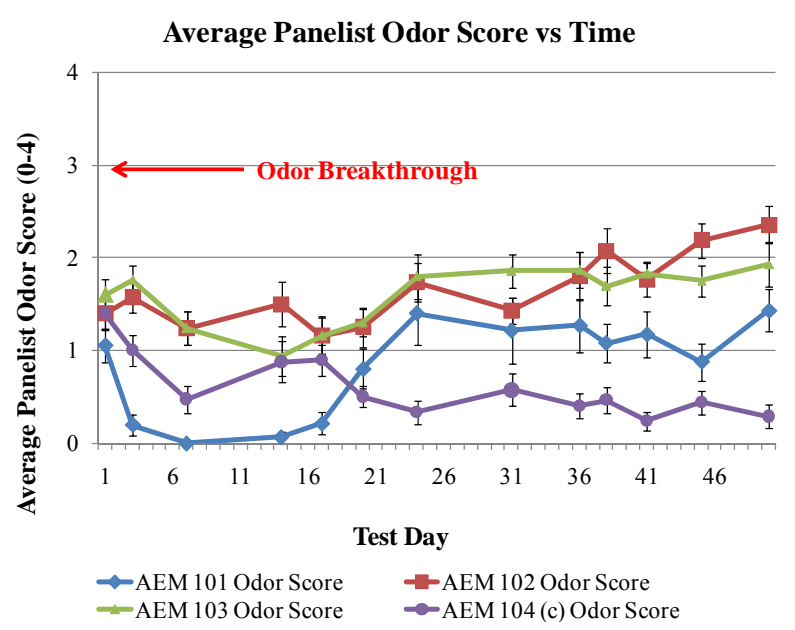

Figure 3. Odor evaluation results of the AEM units. 
units 102,103 , and 104 , and then increased gradually from day 14 to day 50 . This can be attributed to the fact that the odorants from the airstream of the AEM units were removed by the exhaust filter, and that the odor containment performance of the exhaust filter decreased with longer operation duration. The decreased odor control performance of the exhaust filter could be either due to the decrease of active sites, or the increased penetration of other odorants that were not absorbed by the filter with extended operation time.

Despite the elevated odor scores from the AEMs, as shown in Table 1, the odor score for each individual AEM unit and test day was never over 3.0 for the test duration. Furthermore, as given in Table 2, the ammonia concentration in the airstream outlet from the AEM units was maintained below $1 \mathrm{ppm}$. This indicated that activated carbon exhibited the capability to effectively adsorb $\mathrm{NH}_{3}$ on its surface. The ammonia concentration in the AEM internal airstreamvaried in the range of 2.61 $6.30 \mathrm{ppm}$, as detected by the Dräger sensor inserted into the gas sampling port. Thus, the exhaust filter exhibited an ammonia containment efficiency of more than $90 \%$.

The odor removal by the exhaust filter assembled on AEM units suggests combined mechanics of physisorption and chemisorption of $\mathrm{NH}_{3}$ for $\mathrm{H}_{3} \mathrm{PO}_{4}$ loaded activated carbon. Ammonia can be absorbed on activated carbon with pore size similar to its diameter $(<4 \AA)$ by van de Waals forces. Only a small fraction of the activated carbon surface was utilized during the physisorption of ammonia due to the fact that activated carbon hasa larger average pore size (usually $10-20 \AA$ ). The impregnation of $\mathrm{H}_{3} \mathrm{PO}_{4}$ on the surface of activated carbon blocks the pores of activated carbon as a result of pore filling, and thus, creates more micropores that will exhibit higher ammonia removal performance. Another concern about the ammonia adsorption on activated carbon is that the adsorbed ammonia easily desorbs from the surface when being purged by air,as a result of the weak nature of van de Waals forces.

Additionally, the surface acidity of activated carbon is not ideal for ammonia adsorption. This limited the application of activated carbon in ammonia removal as the key factor that dominates the ammonia adsorption capacity of the activated carbon is the surface chemistry, especially the acidic groups [8]. The chemical properties of the carbon surface, especially acidic functional groups, have a strong influence on $\mathrm{NH}_{3}$ adsorption [17]. The impregnation of $\mathrm{H}_{3} \mathrm{PO}_{4}$ on the activated carbon induces acidic groups at the basal planets of the activated carbon, and thus, creates more active sites on the activated carbon surface. Ammonia is a basic gas and the introduction of surface acidity by the impregnation of $\mathrm{H}_{3} \mathrm{PO}_{4}$ promotes the $\mathrm{NH}_{3}$ adsorption capacity on activated carbon via a Brønsted acid-base process [18]. It was reported that the activated carbon impregnated with $\mathrm{H}_{3} \mathrm{PO}_{4}$ has a highly oxidized surface, contributing to the high surface acidity $(\mathrm{pH}<3)[19]$. It was reported that the ammonia was captured on the surface of the $\mathrm{H}_{3} \mathrm{PO}_{4}$-loaded activated carbon through the following chemical reaction to form $\mathrm{NH}_{4} \mathrm{H}_{2} \mathrm{PO}_{4}$ [14]:

$$
\mathrm{H}_{3} \mathrm{PO}_{4}+\mathrm{NH}_{3} \rightarrow \mathrm{NH}_{4} \mathrm{H}_{2} \mathrm{PO}_{4}
$$

Therefore, the creation of acidic functional groups on the surface of activated carboncaused an increase in the amount of chemisorbed ammonia as well as an improvement of physisorption properties at low relative pressures.

The deodorization lifetime of the exhaust filter, as indicated by the breakthrough time, is partially dependent on the amount of $\mathrm{H}_{3} \mathrm{PO}_{4}$ impregnated in the adsorbents [14]. The breakthrough time of the exhaust filter was not obtained in the current study, but the test results showed that the new exhaust filter, which uses phosphoric acid

Table 1. Odor evaluation results from the four AEM units with non-phosphoric acid impregnation exhaust filter.

\begin{tabular}{|c|c|c|c|c|c|c|c|c|c|c|}
\hline \multirow[b]{2}{*}{ Days } & \multicolumn{10}{|c|}{ Odor test scores } \\
\hline & $\mathrm{T}+1$ & $\mathrm{~T}+7$ & $\mathrm{~T}+14$ & $\mathrm{~T}+20$ & $\mathrm{~T}+24$ & $\mathrm{~T}+30$ & $\mathrm{~T}+36$ & $\mathrm{~T}+41$ & $\mathrm{~T}+45$ & $\mathrm{~T}+50$ \\
\hline AEM 101 & 1.05 & 0 & 0.06 & 1.19 & 1.67 & 1.21 & 0.40 & 0.24 & 0.88 & 1.43 \\
\hline AEM 102 & 1.40 & 1.24 & 1.50 & 1.63 & 1.44 & 1.43 & 1.27 & 1.18 & 2.19 & 2.36 \\
\hline AEM 103 & 1.60 & 1.24 & 0.94 & 1.69 & 1.67 & 1.86 & 1.80 & 1.18 & 1.75 & 1.93 \\
\hline AEM 104 (c) & 1.40 & 0.47 & 0.88 & 0.50 & 0.67 & 0.57 & 1.87 & 1.82 & 0.44 & 0.29 \\
\hline Average & 1.35 & 0.82 & 0.83 & 1.12 & 1.64 & 1.50 & 1.64 & 1.59 & 1.60 & 1.90 \\
\hline No. of evaluators & 20 & 16 & 16 & 16 & 15 & 14 & 15 & 17 & 16 & 14 \\
\hline
\end{tabular}

Table 2. Ammonia concentrations in the outlet airstreams of the AEM units.

\begin{tabular}{|c|c|c|c|c|c|c|c|}
\hline \multirow[b]{2}{*}{ Days } & \multicolumn{7}{|c|}{ Ammonia concentration in AEM Outlet, ppm } \\
\hline & $\mathrm{T}+21$ & $\mathrm{~T}+24$ & $\mathrm{~T}+31$ & $\mathrm{~T}+36$ & $\mathrm{~T}+41$ & $\mathrm{~T}+45$ & $\mathrm{~T}+50$ \\
\hline AEM 101 & 0.41 & 0.72 & 0.75 & 0.75 & 0.45 & 0.45 & 0.38 \\
\hline AEM 102 & $<0.20$ & $<0.20$ & 0.26 & 0.27 & $<0.20$ & $<0.20$ & $<0.20$ \\
\hline AEM 103 & $<0.20$ & $<0.20$ & $<0.20$ & $<0.20$ & $<0.20$ & $<0.20$ & $<0.20$ \\
\hline
\end{tabular}


impregnated activated carbon as an adsorbent, could effectively remove ammonia from the exhaust airstream of mouse habitats for a flight mission of at least 50 days.

\section{Conclusion}

A high performance, long duration exhaust filter was developed by NASA Ames Research Center to remove ammonia from the rodent housing Animal Enclosure Module, and $\mathrm{H}_{3} \mathrm{PO}_{4}$ impregnated activated carbon was used as its adsorbent. The odor evaluation results suggested that the exhaust filter can effectively control the odor from the mouse habitats during 45-day (minimum) operation durations, and maintain the odor from AEM units within acceptable levels. The AEM exhaust filter exhibited more than $90 \%$ of overall ammonia containment efficiency. A better understanding of the reaction of exhaust filter against the odorants in the AEM units could be achieved through further identification of specific odor causing components in the exhaust airstream of the AEM units.

\section{Acknowledgements}

The current work was supported by the NASA Ames Research Center Rodent Habitat project.

\section{REFERENCES}

[1] M. Ciganek and J. Nega, "Chemical Characterization of Volatile Organic Compounds on Animal Farms," Veterinarni Medicina, Vol. 53, No. 12, 2008, pp. 641-651.

[2] J. Hartung and V. R. Phillips, "Control of Gases Emissions from Livestock Buildings and Manure Stores," Journal of Agricultural Engineering Research, Vol. 57, No. 3, 1994, pp. 173-189.

http://dx.doi.org/10.1006/jaer.1994.1017

[3] D. H. O'Neill and V. R. Phillips, "A Review of the Control of Odour Nuisance from Livestock Buildings: Part 3, Properties of the Odorous Substances which Have Been Identified in Livestock Wastes or in the Air around Them," Journal of Agricultural Engineering Research, Vol. 53, 1992, pp. 23-50.

http://dx.doi.org/10.1016/0021-8634(92)80072-Z

[4] S. S. Schiffman, J. L. Bennett and J. H. Raymer, "Quantification of Odors and Odorants from Swine Operations in North Carolina," Agricultural and Forest Meteorology, Vol. 108, No. 3, 2001, pp. 213-240. http://dx.doi.org/10.1016/S0168-1923(01)00239-8

[5] L. D. Jacobson, J. R. Bicudo, D. R. Schmidt, S. WoodGay, R. S. Gates and S. J. Hoff, "Air Emissions from Animal Production Buildings," ISAH, Mexico, 2003.

[6] ACGIH, "Threshold Limit Values for Chemical Substances and Physical Agents and Biological Exposure Indices," American Conference of Governmental Industrial Hygienists, Cincinnati, 1992.

[7] Spacecraft Maximum Allowable Concentrations for Air- borne Contaminants, NASA JSC, 1999.

[8] M. Goncalves, L. Sánchez-Garcia, E. de Oliveira Jardim, J. Silvestre-Albero and F. Rodriguez-Reinoso, “Ammonia Removal Using Activated Carbon: Effect of the Surface Chemistry in Dry and Moist Conditions," Environmental Science \& Technology, Vol. 45, No. 24, 2011, pp. 10605 10610. http://dx.doi.org/10.1021/es203093v

[9] A. E. Ghaly and K. N. MacDonald, "Development and Testing of an Ammonia Removal Unit From the Exhaust Gas of a Manure Drying System," American Journal of Environmental Science, Vol. 9, No. 1, 2013, pp. 51-61. http://dx.doi.org/10.3844/ajessp.2013.51.61

[10] F. Stoeckli, A. Guillot and A. M. Slasli, "Specific and Non-Specific Interaction between Ammonia and Activated Carbon," Carbon, Vol. 42, No. 8-9, 2004, pp. 16191624. http://dx.doi.org/10.1016/j.carbon.2004.02.034

[11] T. Bandosz and C. Petit, "On the Reactive Adsorption of Ammonia on Activated Carbon Modified by Impregnation with Inorganic Compounds," Journal of Colloid and Interface Science, Vol. 338, No. 2, 2009, pp. 329-345. http://dx.doi.org/10.1016/j.jcis.2009.06.039

[12] C. Petit, C. Karwacki, G. Peterson and T. Bandosz, "Interactions of Ammonia with the Surface of Microporous Carbon Impregnated with Transition Metal Chlorides," Journal of Physical Chemistry C, Vol. 111, No. 34, 2007, pp. 12705-12714. http://dx.doi.org/10.1021/jp072066n

[13] L. M. Le Leuch and T. J. Bandosz, "The Role of Water and Surface Acidity on the Reactive Adsorption of Ammonia on Modified Activated Carbon," Carbon, Vol. 45, No. 3, 2007, pp. 568-578. http://dx.doi.org/10.1016/j.carbon.2006.10.016

[14] A. Oya and W. Iu, "Deodorization Performance of Charcoal Particles Loaded with Orthophosphoric Acid against Ammonia and Trimethylamine," Carbon, Vol. 40, No. 9, 2002, pp. 1391-1399.

http://dx.doi.org/10.1016/S0008-6223(01)00273-1

[15] K. Maruyama, H. Takagi, M. Kodama, H. Hatori, Y. Yamada, R. Asakura, H. Izumida and M. Mitsuhiro, "Ammonia Adsorption on Porous Carbon with Acidic Functional Groups," TANSO, Vol. 203, No. 208. 2003, pp. 109-113. http://dx.doi.org/10.7209/tanso.2003.109

[16] C. Muller, "Comparison of Chemical Filters for the Control of Airborne Molecular Contamination," Journal of the IEST, Vol. 50, No. 2, 2007, pp. 52-72.

[17] J. Guo, W. Xu, Y, Chen and A. Lu, "Adsorption of $\mathrm{NH}_{3}$ onto Activated Carbon Prepared from Palm Shells Impregnated with $\mathrm{H}_{2} \mathrm{SO}_{4}$," Journal of Colloid and Interface Science, Vol. 281, No. 3, 2005, pp. 285-290. http://dx.doi.org/10.1016/j.jcis.2004.08.101

[18] C. Huang, H. Li and C. Chen, "Effect of Surface Acidic Oxides of Activated Carbon on Adsorption of Ammonia," Journal of Hazardous Materials, Vol. 311, 2008, pp. 311314.

[19] J. Laine, A. Calafat and M. Labady, "Preparation and Characterization of Activated Carbon from Coconet Shell Impregnated with Phosphoric Acid," Carbon, Vol. 27, No. 2, 1989, pp. 191-195.

http://dx.doi.org/10.1016/0008-6223(89)90123-1 